\title{
Mediação e cia: um ensaio sobre os usos sociais do televisor em espaços públicos
}

\author{
Fabrício Silveira ${ }^{1}$ \\ Universidade do Vale do Rio dos Sinos \\ fabricios@unisinos.br
}

\begin{abstract}
Resumo: A televisão encontra-se amplamente incorporada à retórica tecno-midiática que compõe a paisagem urbana contemporânea. Entretanto, ainda são necessários modos de entendimento mais sensíveis às novas dinâmicas de apropriação do meio televisivo no cenário da cidade e atentos, complementarmente, às condições e aos processos de televidência ocorridos também fora do lar. Ancorando-se na descrição de dois casos empíricos - dois bares noturnos localizados na cidade de Porto Alegre -, pretende-se aqui ilustrar o largo leque de situacionalidades públicas em que hoje encontramos o televisor.
\end{abstract}

Palavras-chave: Televisão; cidade; espaço público.

Abstract: The television has been widely incorporated to the technical and mediatic rhetoric who composes the urban landscape contemporary. However, still they are necessary more sensible ways of agreement to the new dynamic of appropriation of this medium in the scene of the city and intent, complementarily, to the conditions and the processes of televisions audiences also occurred out of the home. Anchoring itself in the description of two empirical cases - two located night bars in the city of Porto Alegre -, it is intended here to illustrate the wide serie of public situations where today we find the television set.

Keywords: Television; city; public space.

Resumen: La televisión se ha incorporado extensamente a la retórica técnica y mediatica que compone el paisaje urbano contemporáneo. Sin embargo, son necesárias maneras más sensibles para el entendimiento de la dinámica de apropiación de este medio en la escena de la ciudad y, además, de las condiciones y los procesos de audiencia de las televisiones que también ocurren fuera del hogar. Con base en la descripción de dos casos empíricos - dos bares nocturnos localizados en la ciudad de Porto Alegre -, intentaremos aquí ilustrar una larga serie de situaciones públicas donde encontramos hoy la televisión.

\footnotetext{
${ }^{1}$ Mestre em Comunicação (UFRGS). Doutor em Comunicação (UNISINOS - RS). Professor do Programa de Pós-Graduação em Ciências da Comunicação da Universidade do Vale do Rio dos Sinos (UNISINOS - RS).
} 
Palabras clabes: Televisión; ciudad; espacio público.

Resumé: La télévision a été largement incorporée à la rhétorique technique et mediatic qui compose le contemporain urbain de paysage. Cependant, immobile ils sont des manières plus sensibles nécessaires d'accord au nouveau dynamique de l'appropriation de ce milieu dans la scène de la ville et l'intention, complementarily, aux conditions et aux processus des assistances de télévisions s'est également produite hors de la maison. S'ancrant dans la description de deux cas empiriques - deux barres localisées de nuit dans la ville de Porto Alegre -, on le prévoit ici pour illustrer le serie large des situations publiques où aujourd'hui nous trouvons le téléviseur.

Mots-clés: Télévision; ville; l'espace public.

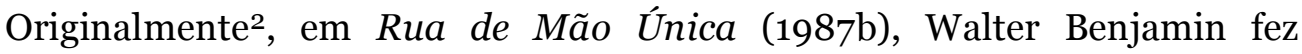
proliferar as alusões ao "denso turbilhão de letras cambiantes, coloridas e conflitantes" que passa a ser lido pelo homem urbano do séc. XIX. "Nuvens de gafanhotos de escritura, que hoje já obscurecem o céu do pretenso espírito para os habitantes das grandes cidades, se tornarão mais densas a cada ano”, dizia ele, percebendo a canalização de certas "tensões gráficas do reclame para a configuração da escrita" e reparando - com algum deslumbramento, podemos talvez supor - a “ditatorial verticalidade" dos cartazes, das placas de sinalização e dos anúncios comerciais. Para Benjamin, a escrita, até então confinada à "arcaica quietude do livro”, estaria começando a levantar-se3. Uma escrita-imagem tridimensional estaria também emergindo. Para Willi Bolle (in SELIGMANN-SILVA, 1999), Benjamin

\footnotetext{
${ }^{2}$ Conforme Richard Sennett (1988), Jean-Jacques Rousseau (1712-1778) foi o maior estudioso e o melhor escritor da vida pública urbana. "Mais do que qualquer um dos seus contemporâneos, Rousseau investigou as grandes cidades [sobretudo Paris] de cima a baixo, como se dissecasse um câncer" (SENNETT, 1988: 147). Nele, teríamos o esboço da primeira teoria da cidade moderna como um ambiente interacional-expressivo. A originalidade de Benjamin, aqui sustentada, diz respeito unicamente ao fato de que é ele quem faz germinar uma abordagem comunicacional mais estrita, lidando já com algumas diretrizes hoje fundamentais na compreensão dos processos midiáticos-comunicacionais: o massivo, os jogos de linguagem, a técnica e o consumo.

3 Em seguida, estes procedimentos de "verticalização da escrita" seriam endossados também pelos jornais e mesmo pelas legendas dos filmes. As citações aqui empregadas foram extraídas de "Guarda-livros juramentado". in: BENJAMIN, Walter. Rua de Mão Única. São Paulo: Brasiliense, 1987b.
} 
reconhece a metrópole moderna, com suas vitrines, passagens e exposições, como o palco de um espetáculo sempre renovado; seus outdoors e suas tabuletas, seus letreiros e seus anúncios luminosos, apresentam-na como uma nova forma de livro.

Desde então, tornou-se praticamente unânime, em diversos recantos disciplinares, o reconhecimento da cidade como texto ou, no mínimo, como suporte de várias escrituras e várias ordens sígnicas, inclusive iconográficas. "Se estudássemos a cidade sob a noção de registros visuais”, comenta Armando Silva (2001: 06), mais recentemente, "seríamos solicitados a compreender um cenário urbano habitado por muitas imagens e o objetivo não seria outro a não ser classificar suas intenções comunicativas, para averiguar em que consiste o seu programa, inerente a cada classe de iconografia".

Apesar disso, ainda são poucos os trabalhos interessados na presença dispersa das telas e dos monitores televisivos no engendramento deste grande sintagma textual, deste grande campo semiótico-imagético que é a metrópole4. Os próprios estudos de recepção, por exemplo, são lacunares no modo como respondem ao exame dessa ordem específica de nossa iconografia urbana. Talvez, essa visível desconsideração temático-metodológica possa decorrer da percepção de que, nesses contextos, justamente o conceito de "audiência" passa a colocar-se também sob suspeita. Como entendê-la, de fato? Como caracterizá-la? Como apreendê-la, nestas condições?5

\footnotetext{
4 Em Imagens eletrônicas e paisagem urbana (Rio de Janeiro: Ed. Relume Dumará, 2002), recentemente publicado, a pesquisadora Beatriz Furtado dedica-se ao tema. Comentários mais detidos encontram-se em http://www.versoereverso.unisinos.br/.

5 Nas duas últimas décadas, como mostra Ien Ang, os estudos quantitativos de audiência, responsáveis pela medição de índices de assistência e do número de monitores ligados (e, conseqüentemente, do número de televidentes presumidos) em determinadas faixas de horário têm passado por sérias (e boas) dificuldades. Os motivos são fortes: "Acciones como zipping [fazer correr velozmente a fita de vídeo durante os comerciais em programas gravados em videocassetes], zapping, cambios de tiempo, etc., son las maniobras tácticas más evidentes y admitidas que los usuários utilizan con objeto de construir su propia experiencia televisiva. Hay muchas otras formas de hacer esto, desde dedicarse a otras cosas al tiempo que se está frente a la pantalla hasta hacer comentarios cínicos sobre los programas em cuestión (...). Como consecuencia de ello, ya no se puede presuponer facilmente - como hacía la lógica fundacional y la estrategia pragmática de las mediciones tradicionales de las audiencias - que tener un aparato de televisión equivale a 'ver televisión', que ‘ver televisión' es lo mismo que prestar atención a la pantalla, que ver un programa conlleva ver también los anuncios intercalados en el mismo (...)" (ANG in SILVERSTONE; HIRSCH, 1996: 203). Acrescente-se ainda a ampliação dos modos de oferta/transmissão televisual: a proliferação das tevês a
} 
Ainda que sejam reconhecidas e mencionadas intermitentemente, continuamos à espera de tentativas mais sistematizadas de compreensão dessa ampla diversidade de 'situações televisivas'. O pesquisador argentino Alejandro Grimson, por exemplo, salienta que os estudos de audiência "se han concentrado básicamente en el estudio de la 'recepción de televisión' en la vida privada" (GRIMSON, 1999: 149), ressentindo-se da "ausencia de una consideración sistemática de la creciente presencia de la televisión en espacios públicos, como bares, aeropuertos y subterráneos".

Seria possível então, como assinala Grimson, pensarmos certos "nãolugares" de nossa "supermodernidade"6 como terrenos ou ambientes sociais em que também se dão vínculos e relações (interações, talvez seja mais apropriado) com a mídia televisiva?

Movendo-se no interior deste campo de intenções, deste conjunto de pistas e diretrizes teórico-temáticas, as páginas que seguem dão destaque a dois locais públicos, cenários de distintas formas de sociabilidade, fluxos variados e distintas estratégias de engajamento interacional, ambos qualificados pela presença altissonante do televisor. Em torno dessa presença - seus modos de ser e repercutir circunscreve-se o foco de nossa descrição. Esperamos que os lugares e os cenários examinados aqui sejam também 'boas ilustrações', satisfatoriamente representativas de outros, infindáveis outros contextos de assistência e uso do televisor que, embora em distintos marcos empíricos, embora portadores de inegáveis nuances diferenciais, a eles possam se assemelhar.

cabo, à qual se somam as outras formas de televisões pagas e as configurações mais recentes da mídia televisiva, tais como a televisão de alta definição (ou HDTV), a tevê por satélite, etc. Nesse quadro de hiper-fragmentação, enorme diversidade de usos, condições de acesso e recursos tecnológicos, torna-se progressivamente inviável determinar o volume objetivo da audiência televisiva. A abordagem etnográfica justifica assim o relevo que tem adquirido nos últimos anos. Aqui, procuramos nos investir de uma atitude investigativa qualitativa, interacional e microscópica - francamente estimulada pelos procedimentos etnográficos.

${ }_{6}^{6}$ Para Marc Augé, três formas de excesso caracterizam a supermodernidade: o excesso de tempo - que nos dá a impressão de "aceleração da história" -, associado ao aumento da expectativa de vida e a uma espécie de 'superabundância factual'; o excesso de espaço, que corresponde também, e muito paradoxalmente, a um 'encolhimento do planeta', devido à rapidez dos transportes, à ronda espacial e atenta dos satélites e, sobretudo, à velocidade e à virtualização das redes técnico-midiático-comunicacionais; e, finalmente, o excesso de ego. "Nas sociedades ocidentais, pelo menos, o indivíduo se crê mundo. Ele pretende interpretar por e para si mesmo as informações que lhe são entregues" (AUGÉ, 1994: 39). 


\section{Cenário o1}

Cavanhas. Trata-se de um bar. Ali são oferecidos lanches rápidos (torradas, cheese-burgeres, pizzas...) e bebidas, principalmente. Situa-se exatamente na esquina das ruas Sarmento Leite e Lima e Silva, no bairro Cidade Baixa, um bairro estudantil e boêmio de Porto Alegre. É o local onde muitos moradores da região fazem as refeições, sozinhos ou em pequenos grupos de amigos, sobretudo à noite. É também "ponto de referência", onde podemos encontrar os conhecidos, disputar uma partida de sinuca ou então jogar conversa fora ao sabor de algumas cervejas. A localização o fato de instalar-se no cruzamento de duas movimentadas ruas - confere uma outra característica à casa: dali pode-se acompanhar o tráfego de automóveis e a circulação casual dos pedestres, principalmente nos finais de semana, quando o trecho torna-se um dos mais agitados da noite na região. O local, portanto, permite que possamos ver e ser vistos, sugerindo a amarra entre visualidade e sociabilidades urbanas.

Como em outros bares das proximidades, há uma ambigüidade e/ou uma indefinição na ocupação do espaço: o interior do estabelecimento, numa quase imperceptível linha de continuidade, confunde-se com o espaço da calçada, reservado usualmente à circulação e à passagem. Um bom número de mesas, em torno de 20 , muito freqüentemente são colocadas logo na faixa pavimentada dos passantes, num raio de poucos metros em relação à fachada e aos limites internos do bar. Outras 20, aproximadamente, distribuem-se dentro do recinto.

Compondo o fundo da peça principal, temos uma fina parede divisória. A partir dali, temos então outra peça, onde se encontram os banheiros e as mesas de bilhar7. O bar funciona a partir das $17 \mathrm{~h}$; fecha por volta das 02h da manhã, ou enquanto ainda houver clientes. Pequenos folhetos e convites para festas espalhamse pelas mesas. Muitas logomarcas - Brahma, Skol, JB, Marlboro, Free - povoam o local. Obviamente, freezers com cervejas e refrigerantes também identificam o cenário.

O público é diverso, representativo talvez do que poderíamos chamar de camada média da população. Geralmente, são profissionais liberais e estudantes

\footnotetext{
7 No final de 2003 - quando já havíamos feito boa parte de nossos registros e anotações do local -, as mesas de bilhar foram removidas. Mesas comuns foram colocadas no local. O televisor, entretanto, permaneceu ali como adereço significante.
} 
vindos do interior do estado. Têm entre 15 e 40 anos. Há muitos casais. Alguns deles acompanham grupos maiores. Não há crianças nem idosos. Todos se alimentam, bebem e conversam animadamente. Nas mesas, de tempos em tempos, os clientes são interrompidos por vendedores de artigos diversos: flores, incensos, leques chineses, fitas cassete, CDs piratas, poemas impressos, cartões e agendas artesanais.

No local, chamam atenção - este é o detalhe que nos interessa - três televisores, dois deles sintonizados geralmente em canais distintos e um outro funcionando como circuito-interno de tevê, com a finalidade clara de conferir maior segurança ao ambiente. Nesse particular contexto de assistência, o televisor figura como elemento técnico-decorativo-funcional. Uma das tevês está no alto de um armário, integrando-se perfeitamente à decoração da casa, cuja unidade está dada também pela combinação de cores e pelo design de mesas e cadeiras. Outro televisor, mais reservadamente, ocupa a peça dos fundos, suspenso no teto, num suporte apropriado, fazendo frente às mesas de sinuca. Ambos são monitores de qualidade, com bons recursos técnicos, tevê a cabo, tela ampla...

Junto ao caixa, há um terceiro monitor, dando a ver o próprio local, naquele exato momento, transmitindo ao vivo, como se estivesse dando segurança (e prestando contas) aos clientes.

O local é muito iluminado. Juntamente com os espelhos afixados nas paredes internas e as faixas de néon que decoram o balcão do caixa, as tevês ativam esta luminosidade. Os televisores em funcionamento parecem responder a uma demanda por "modernidade" e por sintonia na ordem e/ou na rede informacional contemporânea. Sugerem-se também como resposta a uma expectativa de bom atendimento ao cliente, que deve sentir-se em casa, familiarizado e confortável; ainda que esteja sendo monitorado - todo cliente seria um suspeito em potencial? ${ }^{8}$-. Mais enfaticamente, entretanto, a televisão surge ali como pura pulsação iconográfica e

\footnotetext{
8 Detendo-se exclusivamente nas "máquinas de vigiar", nas câmeras e nos monitores de vigilância espalhados estrategicamente em bancos e repartições públicas diversas, Arlindo Machado (1993: 233) afirma que "na tela dos monitores de vigilância, todos parecem suspeitos; até mesmo o mais vulgar dos homens, como nos romances de Kafka, parece acometido de culpa”. Dar continuidade a esta problematização específica - sobre o televisor como aparato de vigilância - implicaria recolocar também a distinção estabelecida por Eliseo Verón entre tecnologia e meio de comunicação (Cf. VERÓN, 1997). Aqui, cabe apenas anotar tal possibilidade de complementação ou desdobramento de nosso debate.
} 
pura luminescência, feixe de luz que atrai o olhar, ponto luminoso no qual não conseguimos, ao menos não tão facilmente, deixar de nos deter. Nem que seja por um breve segundo.

Espalhadas em pequenos grupos, reunidas em torno de cada uma das 40 mesas disponíveis, algumas pessoas sentam-se de costas para o monitor televisivo. Os monitores são vistos da rua, estão apontados e direcionados para a rua, como se estivessem disponibilizando-se, quase determinantemente, para a própria cidade e para os muitos passantes. Quando chega, quer perceba ou não, o cliente coloca-se a questão: acomodar-se voltado para a tela ou para o fervilhar da esquina?

O controle remoto encontra-se com o caixa. Dentre os funcionários (o3 chapistas e 06 garçons), ele é o responsável pela troca de canais e pelo controle dos aparelhos. É ele quem pode, eventualmente, em momentos de menor movimento, quando for solicitado ou quando certos grandes temas se impõem, buscar uma melhor sintonia nos canais, ajustar tonalidades ou mesmo aumentar o volume, simplesmente. As falas dos pedestres e os ruídos da rua misturam-se às conversas dos clientes. Músicas soam alto nos carros que passam. Alguns automóveis buzinam. $\mathrm{Na}$ maior parte do tempo, os televisores encontram-se mudos diante dessa peculiar orquestração de vozes, ruídos e sonoridades urbanas.

De repente, os "gols da rodada" irrompem na tela e motivam comentários em mesas diversas. Assim ocorre sempre que um assunto qualquer desperta atenção. Nos grupos formados em cada uma das mesas, alguém percebe e refere-se à tevê, indicando-a através do olhar ou fazendo um gesto mais brusco para os companheiros. Todos se voltam para a tela. Em seguida, retomam, com outro mote e outro engajamento, o rumo das conversas. Telejornais e esportes, sobretudo, são os programas mais visados. Durante a semana, o local é muito procurado devido à transmissão de jogos de futebol do Campeonato Brasileiro.

\section{Cenário o2}

Jardim Elétrico. Localizado desde fevereiro de 1997, quando foi inaugurado, na Rua da República, também no bairro Cidade Baixa, em Porto Alegre, o bar pode ser definido como um drink bar. Estritamente, não é um lugar para a realização das refeições (para jantar, se fosse o caso), ainda que possamos comer ali alguns pratos 
rápidos, porções de fritas, sanduíches naturais, saladas diversas, etc. Em síntese, é um local para encontros, para beber e conversar. A clientela é formada basicamente por jovens casais e turmas de amigos. O local é muito procurado para a realização de festas de aniversário, por exemplo. Em sua grande maioria, os freqüentadores são estudantes universitários ou recém-formados, entre 20-35 anos, oriundos das classes média e média-alta da cidade. O nome "Jardim Elétrico" faz referência a uma famosa canção do conjunto brasileiro "Os Mutantes”, uma das predileções dos proprietários do estabelecimento. Nas paredes, evidenciando um campo de referências simbólicas talvez indicativas do habitus do grupo (no sentido que Bourdieu dá ao termo9), evidenciando também o clima cultural da casa, o estilo e/ou o gênero musical mais freqüente nas pick ups, encontramos pôsteres de Jim Morrison e The Doors, Jimi Hendrix e Rolling Stones, ícones de amplo apelo pop, dotados ali de charme retrô e revivalista.

Há pouca iluminação, criando-se a penumbra que convém aos namorados. Assim confere-se também um clima de cinema noir ao ambiente. De tempos em tempos, atestando a intenção, pôsteres de Humphrey Bogart e Orson Welles, cartazes e cenas de filmes famosos, sobretudo desse gênero específico, espalham-se pelas paredes. Entrar na casa implica aceitar a consumação mínima (em torno de $\mathrm{R} \$ 10,00)$, o que já cria uma certa restrição de público, um inegável mecanismo de distinção.

Anteriormente, o local havia sido uma garagem. A peça é ampla, o pé-direito é altíssimo e a calçada exatamente em frente ainda mantém o formato de rampa por onde entravam os automóveis. Hoje, o ambiente divide-se em dois pisos: o primeiro é aquele no qual ingressamos imediatamente, quando viemos da rua - ali se encontra o maior número de mesas, o balcão de atendimento, o caixa e o televisor (nosso objeto interessante); ao segundo piso chegamos por uma escada que sobe junto a uma das paredes laterais, posicionada justamente em frente à porta que dá acesso à casa. Ao entrar, escolhemos: ou seguimos em frente, subindo a escadaria que nos levará ao segundo piso, ou, num rápido desvio, corremos ao lado dela, procurando cômodos e

\footnotetext{
9 Na acepção de Bourdieu, o habitus é o conjunto das disposições adquiridas em função do posicionamento neste ou naquele campo social, num ou noutro ponto no interior de um campo sócio-simbólico específico. Assim, o habitus funciona como uma matriz de percepções, apreciações e ações.
} 
mesas disponíveis no primeiro piso. Na verdade, o segundo andar assemelha-se a um grande mezanino, de onde podemos inclusive enxergar, com ângulos de visão um tanto restritos, o entra-e-sai dos clientes no térreo. O próprio televisor também pode ser visto dali. Afixada junto ao balcão do caixa, num suporte maciço e seguro, a televisão se oferece frontalmente àqueles que entram no recinto.

É interessante que a tevê fique, em boa parte do tempo, sintonizada no Cartoon Network. Enquanto conversam e bebem, inquietos nas cadeiras, os presentes acompanham, na órbita do olhar, as peripécias de Frajola, a Vaca e o Frango, Pinky e Cérebro, entre outros, transcorrerem nas 29 polegadas do monitor. Geralmente lúdicos e recreativos - talvez se encontre algo de poético naquele jorro de imagens! -, aqueles conteúdos midiáticos possibilitam rupturas e reinvestimentos conversacionais. Colorida e pulsante, a tela da tevê compõe uma "paisagem natural", na qual podemos perder ou projetar o olhar por alguns instantes. Como contraponto, formando então um envolvente campo de estímulos sensório-perceptivos, soa, ao fundo, a inconfundível trilha musical.

\section{Leitura de cenários}

Os bares Cavanhas e Jardim Elétrico justificam-se aqui como casos representativos, capazes de emblematizar, seja como tendência, seja como estandardização, um conjunto muito maior de contextos afins. O exame dessas 'situações televisivas' específicas deixa à mostra, com suficiente clareza, o engendramento de certos quadros de utilização do objeto-tevê.

Através de um jogo de combinações, estabelecendo e naturalizando associações entre objetos de várias ordens e funcionalidades (objetos de decoração, objetos de design, objetos arquitetônicos, utilitários, imagens publicitárias e ícones da cultura pop), os usos do aparelho televisor são tecidos e entretecidos junto à vivência cotidiana da cidade. No caso, tais elementos são dispostos com vistas à criação de ambientações apropriadas, cenários acolhedores, seja pela praticidade, pela impressão de familiaridade que causam ou então simplesmente porque disponibilizam boas e agradáveis condições para os momentos de lazer. O televisor vincula-se a certas teatralizações urbanas e à construção de cenários de interação, compondo, como elemento fortemente significativo, o palco da sociabilidade. 
As próprias programações televisivas preferencialmente exibidas, num caso e noutro, não são apenas sugestões temáticas, capazes de afirmar ou mesmo de romper, calculadamente, dentro das regras de um acordo não-dito, um dado campo simbólico, um leque de sentidos e expectativas possíveis, mas denotam (ou detonam) também circunstâncias e agenciamentos subjetivos de grupo. De um lado, a factualidade conscienciosa do telejornalismo, a ginástica celebratória do esporte (do futebol, principalmente); de outro, o absurdo poético-onírico, o ludismo desconcertante das comics televisivas.

Juntas, tais situações-tevê representam quebras regradas em relação ao mundo diurno do trabalho e da família. Mesmo assim, procedendo apenas à noite, fora dos limites e dos cerceamentos do lar, nos momentos de distensão e de ócio, ainda carregam certas marcas da televidência doméstica. Entretanto, esses traços são reconfigurados, ora pela intensificação de ênfases anteriormente já dadas, ora pelo acréscimo de novos (e outros) elementos combinatórios. Nesse sentido, há ao menos um aspecto modelar: a relação entre a assistência televisiva e os hábitos alimentares.

Tradicionalmente interessantes à Antropologia ${ }^{10}$, as ritualizações das refeições configuram-se como verdadeiras instituições sociais. Ao possibilitarem uma espécie de comunhão coletiva, remetem à coesão e à unidade do grupo. Entretanto, contemporaneamente, a alimentação parece fragmentar-se de muitas formas: a usual seqüencialização entrada-prato principal-sobremesa já não é tão praticada; perde-se também na fixidez dos horários (e a refeição parece ocorrer agora em horários sempre variáveis, ao sabor das rotinas e dos afazeres de cada um); há uma dessincronização entre horários e lugares de alimentação (hoje, come-se em trânsito, em drive ins ou nas calçadas na frente dos bares, etc), com isso há uma deslocalização do ato de comer, que não se restringe mais apenas à mesa, à cozinha ou à sala de jantar; cozinhar tornou-se uma prática industrial e serializada, como nas cadeias de fast foods, por exemplo; e, além do mais, também desempenhamos muitas

${ }^{10}$ Cf. LÉVI-STRAUSS, Claude. O Cru e o Cozido. São Paulo: Brasiliense, 1986; GOODY, Jack. Cocina, Cuisine y clase. Estudio de sociologia comparada. Barcelona: Gedisa Editorial, 1995. Mais próximo às focalizações comunicacionais stricto sensu, Roland Barthes reserva pelo menos três textos de suas Mitologias (1989) à interpretação da cozinha ornamental, do bife com batatas fritas, do vinho e do leite. Saboreá-los continua sendo um agradável modo de sondar os sentidos segundos e o potencial mitológico (ou "mitologizador") contidos nos produtos da cultura. 
outras atividades enquanto comemos. Historicamente, a assistência televisiva afirmou-se como uma delas. No mundo moderno, como fala Barthes, a alimentação perde em substância e ganha consideravelmente em circunstância. Na funcionalidade da modernidade-mundo, "os alimentos perdem a fixidez dos territórios e dos costumes. Eles se adequam às circunstâncias que os envolvem", diz Renato Ortiz (1994: 87). As situações e os mapas alimentares ajustam-se à polissemia dos contextos.

Como vimos, os televisores animam algumas dessas novas celebrações comensais. Partilhar a mesa das refeições, tanto no lar quanto em restaurantes, bares e demais locais públicos, como mostram os casos observados, é colocar-se também ao alcance da mediatização televisiva. Mais espessa, a associação entre hábitos alimentares e televisuais extrapola hoje o universo doméstico onde começou a engendrar-se. Todavia, mantido e enfatizado o vínculo, o ato de comer e o ato de ver tevê abrem-se progressivamente a interferências tão grandes quanto diversas. Sujeitos às afetações recíprocas, ambos são também atravessados, juntos ou separadamente, pela turbulência da cidade e pela relativa imprevisibilidade dos encontros e desencontros urbanos. Muito surpreendentemente, recuperam-se assim sentidos arcaicos do "comunicacional". Voltando-se à etimologia do termo “comunicação", Luís Martino (in HOHLFELDT et al., 2001) nos lembra que, no universo do cristianismo antigo, communicatio significava o ato de "tomar a refeição da noite em comum". Extraído de sua aparente banalidade, o ato de comer ressemantiza-se, permitindo novamente, ao menos como virtualização, ao menos como ocorrência vicária, "a reunião daqueles que se encontravam isolados".

Se este é um conjunto de situações televisivas ainda pouco contemplado pelas etnografias da audiência, caberia reconhecer, de antemão, alguns traços delineadores/formadores de seu perfil: a simultaneidade e o engajamento precário. Torna-se forçoso, mais uma vez, admitir e sistematizar estes vários modos de espectação televisiva, aceitando, como conseqüência, a suspeita de que não se pode definir de forma essencialista o ato de olhar televisão. Além de complexa, incerta e fundamentalmente ambígua, a prática de assistir tevê constitui também um hábito cultural múltiplo e heterogêneo, cravejado de momentos fortuitos, imprevistos e 
indeterminados. De tal forma que se torna difícil até mesmo estabelecer uma distinção inequívoca entre telespectadores e não-telespectadores.

Nos casos aqui relatados, o telespectador interpela o material midiático colocando-se simultaneamente na condição de cliente, consumidor ou mero passante. Assim definido (ou indefinido), administrando uma heterogeneidade de papéis, re-equaliza os vínculos com as ofertas televisuais, podendo, inclusive, esperar da tevê - e a expectativa é justificada, pois é efetivamente correspondida - funções não propriamente televisivas. Senão vejamos: mais do que artefato de decoração, mais ainda do que simples fundo visual ou do que recurso de atendimento ao cliente, signo de modernização, é saliente o fato de que o televisor venha a funcionar inclusive como puro feixe luminoso. A luminescência do aparelho se projeta no espaço e lhe confere os "climas" adequados ${ }^{11}$. O espectador (?) se deixa aí envolver. Para Muniz Sodré (1994: 32), por exemplo, “a simples visão de qualquer fragmento do mundo miraculosamente produzido no vídeo, a sensação de que o mundo está quase presente ali diante dos olhos, o simples fato de estar ligado o aparelho receptor são elementos capazes de ligar o telespectador". A luminosidade do monitor sustenta uma certa vigília ótica e costura os laços sociais. É Sodré (1994: 63) quem esclarece:

Todo 'fogo', toda iluminação evoca uma presença humana, ainda que esta não se faça imediatamente visível. Em torno da fogueira campestre, da lareira doméstica, sempre houve gente reunida - e não por acaso os alquimistas consideravam o fogo um fator de unificação, algo capaz de remeter a princípios estruturantes, simbólicos, controladores, do grupo. (...) E no que diz respeito à tevê, o vídeo, mesmo quando por um acidente desaparece a imagem, remete, através da pura luminescência, à presença social de todas as outras pessoas. Não é apenas o aparelho que se liga, mas também o telespectador.

Anote-se que o televisor atua também como eixo de atrações ou como diretriz de convergências entre esses (os acima mencionados) e outros monitores. Durante alguns meses, é bom ilustrar, havia uma máquina de pinball compondo, juntamente com a tevê (colocando-se ao lado e um pouco abaixo dela), o cenário do bar Jardim Elétrico. Os usos da televisão - que aqui registramos - parecem remeter

${ }^{11}$ É oportuno lembrar que o mítico Passagen-Werk, de Walter Benjamin, reservaria espaço para a discussão dos "tipos de iluminação". Para Benjamin, os anúncios luminosos produziriam novas escrituras; negativamente, a superabundância de luz provocaria também "cegueiras múltiplas". 
a um campo de associações onde se deposita uma diversidade maior de telas luminosas. Encontrar o televisor desempenhando funcionalidades não-televisivas (decoração e ambiência), vendo-o colocado também como máquina de luz, ou máquina de vigilância, como nossas descrições demonstram, é indicar a necessidade (excessiva, no que diz respeito aos nossos propósitos imediatos e nossas intenções pontuais de investigação) de uma antropologia das telas urbanas. Até mesmo alguns anúncios luminescentes, displays publicitários e vídeo-textos poderiam ser aí considerados. Ao que consta - é Alejandro Grimson (1999) quem recorda -, Roger Silverstone já fizera a sugestão. Esta perspectiva apenas incluiria os televisores esparramados pelo espaço público, sujeitos ou não à operatividade da mediatização. A descrição de cenários de assistência televisiva seria apenas um fragmento/componente (ainda que importantíssimo!) nessa promissora formulação.

Somente o acúmulo de tais inscrições e de tais materiais empíricos revelaria com maior nitidez o potencial explicativo e a sustentação de certos operadores conceituais que hoje recobrem o campo de estudos sobre os processos e os produtos midiático-massivos. Compulsoriamente, seríamos conduzidos à forja de categorias analíticas - tanto melhor quanto mais operacionalizáveis - que fizessem frente a certas estabilidades hermenêuticas (interpretação racional - verbalizada ou percebida - de conteúdos/programas) e situacionais (espaço-tempo muito rigidamente concebidos) com que a audiência, por exemplo, ainda é pensada. Assumindo a crise do espaço substancial (contínuo e homogêneo), seria possível entender os contextos de televidência em espaços acidentais (descontínuos, evanescentes e heterogêneos)? De que forma? Na constelação da cultura visual contemporânea, como assimilar, compreensivamente, a instabilidade generalizada da imagem televisiva, cujo tempo de sensibilização parece escapar - nos casos aqui reunidos - à nossa concentração e à nossa consciência imediata? Tais questões são indícios de que deveríamos nos arriscar na confecção de ferramentas teóricas mais fluidas e flexíveis, capazes de aderir com maior fidelidade à engenharia inventiva e à processualidade um tanto insondável destes usos/consumos midiáticos.

Em nosso caso, por exemplo, a idéia de mediatização não responde de forma totalmente satisfatória às ênfases antropológicas e não-hermenêuticas que procuramos aqui oportunizar. Essa insuficiência teórica (decorrente, logicamente, 
dos objetivos e das posturas de nossa problematização) pode ser compensada pela noção de medialidade, oferecida por Hans Ulrich Gumbrecht (conforme Felinto [2002]). Em síntese, a noção reclama a consideração de todos os traços materiais envolvidos na constituição, nos agenciamentos e nos múltiplos modos de acoplagem dos instrumentos tecnológicos às experiências e vivências dos sujeitos. "[A tecnologia] sempre é também 'incorporada' e 'vivida' por seres humanos que se envolvem nela dentro de uma estrutura de sentidos e metáforas, na qual as relações sujeito-objeto são cooperativas, co-constitutivas, dinâmicas e reversíveis”, lembra um dos textos reunidos por Gumbrecht e Karl Ludwig Pfeiffer no volume Materialities of Communication (apud FELINTO, 2002: 41). Assim, no manejo deste norte conceitual, contemplaríamos melhor a materialidade pragmática e o sensualismo técno-corpóreo que também presidem nosso relacionamento com as mídias no horizonte fervente e na abertura sufocante das metrópoles. Focalizar o televisor em sua medialidade seria dar convergência analítico-interpretativa às observações que fizemos sobre o espantoso leque de usos e funcionalidades (televisivas e nãotelevisivas) da tevê na arena vivida da cidade.

Entretanto, o exame cartográfico ou genealógico dessa família de conceitos (mediação, mediatização, medialidade - e poderíamos acrescentar aí, talvez como inauguradora da linhagem, a idéia benjaminiana da reprodutibilidade técnica) reserva-se como possível seqüência de aprofundamento. Abordar intrinsecamente os conceitos, apurar suas correspondências exatas, suas origens e filiações, suas condições mais comuns de aplicabilidade, as ênfases priorizadas, caso a caso, são tarefas reservadas para outro momento, talvez para um próximo trabalho, visto que demandariam renovado e vigoroso fôlego. Agora, de forma relativamente extrínseca à pura discussão conceitual, basta cotejá-los às situações televisivas efetivamente averiguadas. Cabe-nos tão somente deixá-las solicitar/regular os instrumentos conceituais através dos quais encontrarão, no futuro, escuta mais adequada. 


\section{Referências bibliográficas}

ANG, Ien. Las guerras de la sala de estar. Nuevas tecnologias, índices de audiencia y tácticas en el consumo de la televisión. in: SILVERSTONE, Roger; HIRSCH, Eric (orgs.). Los Efectos de la Nueva Comunicación. El consumo de la moderna tecnologia em el hogar y en la família. Barcelona: Bosch, 1996, p.193-211.

AUGÉ, Marc. Não-Lugares. Introdução a uma antropologia da supermodernidade. Campinas: Papirus, 1994.

Por Uma Antropologia dos Mundos Contemporâneos. Rio de Janeiro: Bertrand Brasil, 1997.

BARTHES, Roland. Mitologias. $8^{\text {a }}$ ed. Rio de Janeiro: Ed. Bertrand Brasil, 1989. (Edição revista e ampliada: Rio de Janeiro: DIFEL, 2003.)

BENJAMIN, Walter. Magia e Técnica, Arte e Política. Ensaios sobre literatura e história da cultura. Obras Escolhidas. $3^{\text {a }}$ ed. São Paulo: Brasiliense, 1987a.

Rua de Mão Única. Obras Escolhidas II. $5^{\mathrm{a}}$ ed. São Paulo: Brasiliense, 1987b.

- Charles Baudelaire. Um lírico no auge do capitalismo. Obras Escolhidas III. $1^{\text {a }}$ ed. São Paulo: Brasiliense, 1989a.

BOLLE, Willi. Fisiognomia da Metrópole Moderna. Representação da história em Walter Benjamin. $2^{\text {a }}$ ed. São Paulo: FAPESP/EDUSP, 2000.

BUCK-MORSS, Susan. Dialética do Olhar. Walter Benjamin e o Projeto das Passagens. Belo Horizonte - MG: Ed. UFMG; Chapecó - SC: Ed. Argos, 2002.

FELINTO, Erick. "Materialidades da Comunicação": por um novo lugar da matéria na Teoria da Comunicação. Texto apresentado no GT Epistemologia da Comunicação, no X Encontro Nacional da Compós, UnB, Brasília - DF, 2002.

GRIMSON, Alejandro; VARELA, Mirta. Audiencias, Cultura y Poder. Estudios sobre la televisión. Buenos Aires: Editorial Universitaria de Buenos Aires (EUDEBA), 1999.

GUMBRECHT, Hans Ulrich. Modernização dos Sentidos. São Paulo: Ed.34, 1998a.

. Corpo e Forma. Ensaios para uma crítica não-hermenêutica. Rio de Janeiro: Ed. UERJ, 1998b.

MACHADO, Arlindo. Máquina e Imaginário. O desafio das poéticas tecnológicas. São Paulo: EDUSP, 1993. 
. A Arte do Vídeo. $2^{\mathrm{a}}$ ed. São Paulo: Brasiliense, 1990.

MARTÍN-BARBERO, Jesús. Dos Meios às Mediações. Comunicação, cultura e hegemonia. $2^{\text {a }}$ ed. Rio de Janeiro: Ed. UFRJ, 2001.

ORTIZ, Renato. Mundialização e Cultura. São Paulo: Brasiliense, 1994.

SELIGMANN-SILVA, Márcio (org.). Leituras de Walter Benjamin. São Paulo: FAPESP; Annablume, 1999.

SENNETT, Richard. O Declínio do Homem Público. As tiranias da intimidade. São Paulo: Cia. das Letras, 1988.

SILVA, Armando. Imaginários Urbanos. São Paulo: Perspectiva; Bogotá: Convênio Andrés Bello, 2001 (trad.: Pérola de Carvalho e Mariza Bertoli).

SILVERSTONE, Roger. Televisión y Vida Cotidiana. Buenos Aires: Amorrortu, 1996.

; HIRSCH, Eric (orgs.). Los Efectos de la Nueva Comunicación. El consumo de la moderna tecnologia em el hogar y en la família. Barcelona: Bosch, 1996.

; HIRSCH, Eric; MORLEY, David. Tecnologías de la información y de la comunicación y la economía moral de la familia. in: SILVERSTONE, Roger; HIRSCH, Eric (orgs.). Los Efectos de la Nueva Comunicación. Barcelona: Bosch, 1996, p.39-57.

SODRÉ, Muniz. A Máquina de Narciso. Televisão, indivíduo e poder no Brasil. $3^{\text {a }}$ ed. São Paulo: Ed. Cortez, 1994.

VERÓN, Eliseo. Esquema para el análisis de la mediatización. Diálogos de la Comunicación. IX Encuentro Latinoamericano de Facultades de Comunicación Social, n.48, 1997, p.09-17. 